University of San Diego

Digital USD

Spring 5-27-2017

\title{
Implementation of Screening Guidelines to Improve Quality of Care in a Small, Ethnically Diverse Pediatric Primary Care Practice...Then What?
}

Brooke Basford

University of San Diego, brookebasford@sandiego.edu

Follow this and additional works at: https://digital.sandiego.edu/dnp

Part of the Nursing Commons

\section{Digital USD Citation}

Basford, Brooke, "Implementation of Screening Guidelines to Improve Quality of Care in a Small, Ethnically Diverse Pediatric Primary Care Practice...Then What?" (2017). Doctor of Nursing Practice Final Manuscripts. 38.

https://digital.sandiego.edu/dnp/38

This Doctor of Nursing Practice Final Manuscript is brought to you for free and open access by the Theses and Dissertations at Digital USD. It has been accepted for inclusion in Doctor of Nursing Practice Final Manuscripts by an authorized administrator of Digital USD. For more information, please contact digital@sandiego.edu. 
Implementation of Screening Guidelines to Improve Quality of Care in a Small, Ethnically Diverse Pediatric Primary Care Practice...Then What?

Brooke Basford, BSN, DNP Student 


\begin{abstract}
Although best practice guidelines have been shown to be effective, the process of translation into everyday practice can be challenging. The purpose of this evidence-based project (EBP) was the implementation of standardized screening tools into annual well-child visits in a small, ethnically diverse pediatric primary care practice in southern California. Standardized screening is recognized as an important process in identifying conditions early to facilitate early intervention. The practice site identified obesity has a priority and consequently the Department of Health Care Services: Child Health and Disability Prevention (CHDP) Program Guidelines for Diet and Nutrition Screening for Children assessment form was implemented in children aged 518 years with a body mass index (BMI) of greater than 95\%. Additionally, a lack of standardized screening for autism was identified as an additional practice need. The Modified Checklist for Autism in Toddlers-Revised (MCHAT-R) was implemented at the 18-month well-child check. The results of this EBP project was the successful implementation of obesity and autism screening tools with an uptake of $77 \%$ and $60 \%$ respectively. Additionally, obese patients were offered student nurse practitioner led weight management education sessions, resulted in low uptake (24\%).
\end{abstract}

Keywords: Pediatric, Primary care, screening tools, obesity, autism, diverse, child 


\section{Problem Description}

The American Academy of Pediatrics (AAP) and National Association of Nurse Practitioners (NAPNAP) have long advocated for standardized screening to begin in the pediatric primary care setting because of the frequency of scheduled routine visits that are recommended for well child care. These organizations recommend adoption of standardized instruments to identify children at risk for conditions that threaten their future health, of which obesity screenings and developmental screenings are included. Despite guidelines and recommended standardized screening, uptake remains low (AAP, 2011; Porter et al., 2016; Zwaigenbaum et al., 2015).

\section{Background and Significance}

The use of screening tools in the primary care setting is considered one of the most important functions of pediatric primary care providers. Children are often seen many times for well child visits and this allows providers to trend children over time. The AAP and NAPNAP have both issued policy statements regarding the importance of screening children for both obesity and developmental delays (Barlow, 2007; Radicki et al, 2011).

\section{Obesity Screening}

Currently, childhood obesity is a growing national epidemic with one out of three children classified as overweight and obese (Brandt, Booker \& McGrath, 2013). Overweight for children is a $\mathrm{BMI}$ of $>85^{\text {th }} \%$ to $95^{\text {th }} \%$ and obese is $\mathrm{BMI} \geq 95^{\text {th }} \%$ respectively (Barlow, 2007). Because of the increasing trend of overweight/obese children, primary care providers are asked to take an active role in the treatment and identification of obese children (Ebbeling \& Antonelli, 2015). 
Efforts to prevent and treat pediatric obesity include recommendations of structured weight management programs that escalate in a stepwise manner originate within the primary care setting. There are four stages that are proposed. Stage 1 is "prevention plus", which focuses on providing education regarding diet and activity. These are basic interventions and easily met within the primary care setting. Stage 2 and 3 are deemed to be structured weight management programs with multidisciplinary teams that involve nutrition support and behaviorists. Stage 2 can be applied in the primary care setting as well. Stage 3 involves management partners that are not part of the primary care practice. Stage 4 is the most intensive and requires coordination with outside facilities

Research also suggests that $80 \%$ of providers in the pediatric primary care setting report feeling dissatisfaction during conversations with patient about obesity (Gruhl \& Van Leuven, 2014). The importance of decreasing obesity within the pediatric population is very clear because this is the first generation that is expected to have shorter lifespans than previous generations (Cygan, Baldwin, Chehab, Rodriguez \& Zenk, 2014).

\section{Autism Screening}

Another childhood condition that is of growing concern is autism. According to Radecki et al. (2011), standardized screening tool use for developmental delay has doubled over the span of 2002-2009. Despite this increase, less than half of the providers that responded to the survey provided standardized screening in children less than 36 months. The CDC (2014) estimates that 1 in 68 children have an autism diagnosis by age 8. Current AAP recommendations include developmental surveillance at each well-visit, with targeted developmental screenings at the 9 and 18 month well visits. The importance of identification before age 3 is emphasized because core deficits of autism can be mitigated with early intervention and services (Zwaigenbaum et 
al., 2015). Despite the availability of current detailed guidelines with proven advantages for early identification of autism, rates of autism and developmental standardized screening continue to have low uptake (Zwaigenbaum et al., 2015).

\section{Models and Frameworks used for EBP}

This project was guided by the Iowa Model for the identification of practice problems and implementation of solutions based on the available evidence. The "trigger" for practice change was the identification of two practice priorities: 1) Lack of structured follow-up and education for children screened as overweight or obese. 2) Absence of a standardized method for screening for autism. As a result, a team consisting of the entire pediatric practice was formed and the evidence was reviewed for existing guidelines and recommendations. After examination of the literature, pursuing standardized assessment of obesity and screening for autism were found to be important practice goals. The implementation of screening guidelines was trialed as pilot processes for each tool respectively. The Department of Health Care Service: Child Health and Disability Prevention (CHDP) form that assessed nutrition and activity was selected as the tool for obesity assessment. The Modified Checklist for Autism in Toddlers-Revised (MCHATR) was selected as the standardized tool to screen for autism at the 18-month visit. (Titler, 2010).

During the process, there were opportunities for assessment of process and effectiveness in implementation. Assessment and identified modifications during the implementation phase, the Plan-Study-Do-Act (PSDA) framework guided the project progress. The PDSA cycle promoted constant assessment and allows for adjustments in current process based project outcomes (AHRQ, 2013).

Motivational interviewing was also used during the implementation of Stage 2, a standardized weight management program with children identified as having greater than $95^{\text {th } \%}$ 
BMI with a diagnosis of obesity. Motivational interviewing is a conversational method that helps to determine intrinsic motivation and assessing current state of readiness (Dobber, Scholte van Meijel, Barkhof, Scholte op Reimer, Latour, Peters \& Linszen, 2014). In a randomized controlled trial study, motivational interviewing with parent support was shown to be an effective strategy for changing obesity related behaviors. Parental involvement was shown to be an important factor in the improvement of anthropometric measures for obese children (Pakpour, Gellert, Dombrowski \& Fridlund, 2014). Although formal motivational interviewing training is recommended, the nurse practitioner (NP) student reviewed the AAP recommended conversational dialogue practice and videos (AAP, 2015). The video demonstrated concepts and techniques were incorporated into the structured weight management NP student led educational sessions.

Another aspect that guided this project was the formulation of a PICOT question. PICOT stands for patient population, intervention to be implemented, comparison intervention, outcome and time frame (Melynyk \& Fineout-Overholt, 2011). According to Melnyk and Fineout-

Overholt (2011), this is an important step in the process of determining the clinical significance of the evidence based project. The PICOT question for this project

P: 1. All children were screened for BMI but there was a lack of follow up education for the $18 \%$ with a BMI greater than $95^{\text {th }} \%$.

2. No systematic screening for autism in place for the practice.

I: $\quad$ 1. Implement secondary screen for greater than $95 \%$ BMI \& refer for flexible goal-setting education.

2. Initiate MCHAT screen at all 18 month visits.

C: $\quad$ Compare screening rates 4 months' post- intervention. 
O: $\quad$ Screening and education uptake rates.

T: $\quad$ Total project time including pre-post intervention will be 7 months.

\section{Project Planning and implementation}

The aims of this project were twofold. The first was to increase appropriate and consistent use of primary care screening tools during well-visits, in accordance with the AAP and NAPNAP recommendations. The second aim was to implement a pilot of the obesity assessment tool that would augment existing obesity screening within the practice for those children with a BMI greater than $95^{\text {th } \%}$ and an autism tool. The tools were selected for their accessibility and relevance. The overarching purpose of the project is to fine-tune the screening implementation process within the pediatric practice to allow other screening tools to be seamlessly integrated into the practice workflow.

This process improvement project was implemented in a culturally diverse pediatric primary care practice in Southern California. The practice consists of two pediatricians, one nurse practitioner (NP), three medical assistants, one front desk staff member and one office manager. There are over 2,300 patients enrolled to the practice with about 7200 encounters per year. Most of the patients are publicly insured (51\%), 45\% have private insurance, and 4\% pay cash. The practice is ethnically diverse represented by a large percentage of Hispanic, nonHispanic white, non-Hispanic black, Asian, and mixed ethnicities.

A needs assessment was conducted, practice guidelines were reviewed and current workflow was observed to optimize project success. Lastly, gaps were identified between current practice and recommended guidelines. Key stakeholders identified pediatric obesity as a major concern for the practice and chose this topic as the initial focus for translation to practice including planned adoption of additional screening guidelines to follow. 


\section{Review of the literature}

Translation of evidence based practice into everyday healthcare practice occurs very slowly. A systematic review found only a 33\% uptake of recognized guideline (Lau, Stevenson, Ong, Dzidzic, Trweek, ...Murray, 2016). This review demonstrates that although best practices are recognized and recommended, translation of evidence into everyday workflow can be challenging. There are many facilitators and barriers that affect successful implementation of guidelines (Lau, Stevenson, Ong, Dzidzic, Trweek, ...Murray, 2016). Pediatric nurse practitioners can play a key role in the dissemination of best practices and identifying the gaps between research and practice (Lindeke, 2015). The American Academy of Pediatrics (AAP) and National Association of Pediatric Nurse Practitioner (NAPNAP) recommends assessment for obesity at each well visit and standardized screening for autism at the 9 month and 18 month well visits in the pediatric primary care settings (Barlow, 2007; NAPNAP, 2015; Zwaigenbaum et al., 2015).

It is not surprising that early screening leads to better healthcare outcomes because this allows for earlier diagnosis, treatment and interventions. Cleave and colleagues (2016) conducted a systematic review of 23 articles that reviewed evidence based interventions that increased pediatric screening. The researchers determined that there was a myriad of achievable actions that providers and staff can utilize to increase screening. They determined that the implementation of an intervention within the pediatric setting increased compliance and results were significantly higher if pre-intervention screening was modest. Interventions included introducing screening into existing workflow, providing guidance on the change project and adjusting staff responsibilities. The researchers also acknowledged that no one intervention was superior than others but stated that quality improvement initiatives with continuous evaluation 
were effective strategies that support pediatric screenings. Researchers have also shown that evidence based practice guidelines are more successful in practice when nurses believe that the interventions will improve the quality of patient care and when a problem is recognized there is an identified intervention when it is identified within the practice itself as necessary for the practice (Nordstrand, Fridlund, \& Sollesnes, 2016).

The development of student nurse practitioner led educational sessions aimed at families who children were $>95^{\text {th }} \%$ for weight and was modeled using AAP recommendations and guidelines. Educational sessions were designed to target specific behaviors that are known to contribute to obesity and if corrected may decrease child's BMI. The AAP recommends targeting the following behaviors: eliminating consumption of sugary drinks (including juice), increasing fresh fruits and vegetables intake, limiting screen time to less than 2 hours per day and participating in at least 60 minutes of activity per day (AAP, 2015). While this list is not all inclusive, it provided the basis of the educational sessions. Part of these tailored sessions was to involve the parents in the goal setting and family behavioral changes as this has been shown to be effective treatment for childhood obesity (Coppock, Riddolfi, Hayes, St. Paul \& Wilfley, 2014). Assessing readiness for change utilizing motivational interviewing (MI) and nonjudgmental dialogue were the keys to determine intrinsic commitment of the patient and family. MI is endorsed by the AAP as an effective strategy for partnering with patients/families and promoting healthy behaviors changes (2016). Patient directed goals were based on readiness to change. The student nurse practitioner would guide and ensure that the goals were reasonable, timely and attainable. 


\section{Implementation Process}

\section{Obesity}

While conducting the practice needs assessment, it was determined that the practice was only partially meeting AAP recommendations for identification and treatment for childhood obesity. The practice was conducting 100\% BMI's on children greater than 5 years of age during well child visits, referred patients to nutrition and obtained obesity labs. The practice was also collecting data via their intake sheet that asked if parents "were concerned about their child's weight". This key question would often prompt the provider to begin the dialogue about weight management and provided the parent's perspective of their child's weight. This was not formally documented and was used internally as a starting point for readiness. The prevalence of obesity within the practice was pervasive and the key stakeholders selected to provide obesity treatment within the practice in accordance with the AAP recommendations. The practice proposed the addition of an additional obesity assessment tool to determine focus areas to address during the visit for those at highest risk of future health consequences. Additionally, weight management education sessions were made available if desired.

The form selected was the State of California- Child Health and Disability Prevention: Nutritional and Activity Assessment form for obese children with greater than $95^{\text {th }} \%$ BMI's, aged 5 years old and older. This form assesses activity level, food choices, and screen time to help guide weight management education. After check in, the provider determined BMI status based on height, weight and age of the child. Subsequently, if the child was $>5$ years old with a BMI greater than $95^{\text {th }} \%$, then the form was presented to parents for completion and explanation of purpose. Additionally, those children identified as obese were offered tailored and individual weight management educational sessions. A student nurse practitioner student used motivational 
interviewing with the parents and child if appropriate, to help them identify specific goals for their child. Parents have a wide choice of how they wanted to receive the education including text, telephone, email or face to face meetings.

\section{Autism}

The autism screening tool implementation was the second screening to be implemented within the practice. The practice determined that screening for autism was an additional need and under the umbrella of screening tool implementation, would be added to the project. A needs assessment revealed that the practice setting did not engage in consistent standardized developmental screening for autism. AAP recommends screening for autism at the 9, 18 and 30 (24 month) month well-child visits. The practice selected to screen for autism at the 18 month well child visit. Therefore, the project of implementation of standardized screening tools was expanded to add autism screening at the 18-month visit.

This tool was introduced using a different workflow approach which was front desk driven by appointment type. This form was given out by the front desk staff at check-in for parents/caregivers bringing a child for an 18-month well child visit. Parents completed the form while waiting to be seen. It was scored by the provider and discussed with the parent/caregiver during the visit. Referrals to appropriate services were provided based on the MCHAT-R scoring.

\section{Benchmark Targets}

\section{Obesity}

The established practice goal for the CHDP assessment obesity tool was $70 \%$ screening rate among those eligible. This benchmark was consistent with a systematic review that 
examined compliance with obesity screening in pediatric primary care settings (Cleave et al., 2016).

\section{Autism}

Although the Center for Disease Control (CDC) reported that only $20 \%$ of families receive the AAP recommended developmental screenings during well child visits per parental report (CDC, 2014). The benchmark for this project was also set at $70 \%$ for the pediatric primary care practice as determined by practice leadership.

\section{Results}

Baseline rates were identified using retrospective electronic health record reviews from May 2016-July 2016. The screening practices were implemented into the practice from August 2016 through November 2016 and therefore contains four months of post-intervention data. Screening data was mined from the practice's electronic health record (EHR).

\section{Obesity Screen}

The records were reviewed to determine if standardized assessments involving nutrition and activity were completed for children greater than 5 years old identified as obese. The CHDP screening tool was counted as complete if it was scanned into the EHR or if it was documented as completed in the "plan and assessment". Measures assessed included the review of electronic health records by the student pediatric nurse practitioner using tallied totals of all well child visits during project period with children 5 years old and older, those identified as obese (BMI greater than $95^{\text {th }} \%$ ).

The results of this quality improvement evidence based project demonstrated successful implementation of the secondary screening of children who were obese at $77 \%$. Of the 452 children seen aged 5 years and older, 82 of them had a BMI $95^{\text {th }} \%$ or $18 \%$ of the well child 
visits in the target age range. The children who received the secondary screen ranged in age from 5-18 years old. The race/ethnicity of these children was the following: $45 \%$ Hispanic, $16 \%$ NonWhite Hispanic, 7\% Non-Hispanic African American, 6\% mixed races, 5\% Pacific Islander and 3\% Asian. (see Appendix A)

Parental concern data collected via the practice intake form indicated that $55 \%$ of parents were concerned and 45\% were 'not' concerned about their child's weight. When separated out by gender and ethnicity, overall, non-white Hispanic parents were most concerned and white non-Hispanic parents were least concerned. The literature supports that obesity rates are highest in non-Hispanic blacks, Hispanics and low socioeconomic status children (Humpi et al, 2011). (see Appendix B1)

Overall obesity rates in the practice were determined to be $18 \%$ during the project assessment phase. Although the obesity rates were high, many parents/caregivers did not participate in the additional weight management sessions that were offered by the student nurse practitioner despite being offered a wide array of delivery methods. The educational sessions were offered via in clinic meetings, phone calls, text messages and emailed modalities. Parents were offered a variety of communication methods to increase participation. Only $24 \%$ of the parents of children identified as obese participated in one or more of the tailored and individualized student nurse practitioner led weight management education sessions. (see Appendix B2)

\section{Autism Screen}

It has been documented that early identification of obesity and autism allows for early diagnosis and intervention (AAP, 2015; Zwaigenbaum et al, 2015). All 18-month well visit charts were reviewed between August through November 2016 to determine if the MCHAT-R 
was administered, completed and scored. This process relied on accurately noting visit type on the schedule and relied on scoring of the screening by the provider.

There were several occasions where the MCHAT-R was noted as being utilized and scored, but the form was not physically scanned into the chart. These were counted as screenings that were completed and noted if resource referrals were indicated. Among the 54 children seen for the $18^{\text {th }}$ month well child visit between August and November, only 24 had a completed MCHAT-R form (60\%). Out of those children screened, none screened positive and therefore no referrals were placed. Although the practice did not meet the autism screening benchmark of $70 \%$, it was trending upwards and if the trend continued, with more follow-up time, it may have met the set benchmark. (see Figure 3)

\section{Cost/Benefit}

Determining the cost to benefit ratio of a quality improvement project is an important part of determining the sustainability of a project. The project must also change practice providers and staff behaviors to be called cost effective. (Thompson, Pulleyblank, Parrott, \& Essex, 2016). Obesity

The cost of implementation of the CHDP was very low to the practice. The student's time was free and educational sessions occurred during scheduled staff meetings. The CHPD form was free and available for reprint via the internet. In contrast, the advantage of early screening, identification, diagnosis and treatment of obesity have long term health benefits. Obesity increases risks for long term health consequences such as hypertension, diabetes, cardiovascular disease, and metabolic syndrome. Additionally, overweight children greater than $85^{\text {th }} \% \mathrm{BMI}$ at age 5 years have a fourfold risk of being obese by age 14 . 
Children that are obese at in childhood and adolescents have an increased risk of continuing the obesity trend and becoming obese adults (NAPNAP, 2015). Although implementation was successful in the practice, the sustainability of the CHDP form does not look favorable as the form was described by staff as being time consuming and burdensome.

\section{Autism}

The cost of implementation of the MCHAT-R screening was also very low and again the student's time was free. The autism screening form was available via the internet and easy to download. The cost benefits to early screening, identification, diagnosis and treatment is documented in the literature. The earlier treatment is initiated the timelier the referrals and appropriate services are acquired (AAP, 2006). Although the autism screening did not meet the established benchmark, the sustainability of the MCHAT-R screening looks highly favorable as it was found to be easy to use by staff and is fully aligned with the AAP recommendations.

\section{Conclusions}

This project speaks to the urgency involved in identifying facilitators and barriers to the adoption of evidence based practice and guidelines into pediatric primary care practice (Quanbeck et al, 2016). The conclusion of this quality improvement project is that successful implementation of standardized screening tools is possible in a small, diverse private pediatric practice. Qualitative methods were used to explore the facilitators and barriers of implementation from the provider and staff perspective. These included open ended questions that solicited answers to the following questions: "What was difficult about implementing the assessment and screening tools?" and "What was easy about implementing the assessment and screening tools?" 


\section{Obesity}

Providers and staff responded to the question of what made the CHDP obesity assessment form easy to implement. Practice providers stated that it facilitated targeted education and that it provided parents a visual awareness of the current state of nutrition and activity for their child. Some of the barriers expressed included that the CHDP form was time consuming, parent declined frequently to fill out form due to lack of perceived importance and if the form was forgotten in the beginning of the visit it was not convenient to go back into the office to retrieve. The literature supports lack of time and resources as one of the largest barriers to implementing standardized screening (Radecki et al, 2011).

\section{Autism}

Qualitative assessment of facilitators of the autism screening tool implementation was that the staff found the tool easy to reproduce and parents were willing to complete the form. Providers found the tool easy to score and not time consuming. Identified barriers were if there was a scheduling error and the form was not placed on chart, then it was not convenient to leave the room to retrieve.

Overall, applicable to both screening tools, barriers to sustainability include the high turnover of office staff. One of the most impactful limitation was the electronic health record and the lack of ability to readily pull data. This led to manual record review which increases the potential for human error and is time consuming.

\section{Comparison of EBP Project with the Literature}

\section{Obesity}

The project results of parental concern regarding their child's weight was consistent with the literature. According to White et al (2016), 77\% of parents perceived their child's weight 
falsely. Researchers demonstrated that parents did not understand how weight categories were defined and did not understanding the BMI concept as a weight measure. High attrition rates in weight management programs for children is well documented (Hampi et al, 2011). This is consistent with the project's results. Of the three families that elected to participate in educational sessions, only three families continued past week 3 . According to researchers, some common predictors of weight management program drop out include Medicaid participants, parents with increased BMIs, perceived lack of benefits, and location and timing of program (Hampi et al, 2011). The student practitioner queried several parents as to what influenced their decision to stop participating. Their answers were also consistent with the described reasons above.

\section{Autism}

According to the CDC (2014), only $20 \%$ of pediatric patients receive the AAP recommended developmental screening during well visits using parental report. Although the project markedly increased 18 month screenings to $60 \%$, well above the national average rate of $20 \%$, it did not meet the project benchmark of $70 \%$. Providers that use clinical surveillance alone, without the use of a standardized screening missed $45 \%$ of children that would have been met criteria for intervention programs (Porter et al, 2016). There were no identified positive screenings in the practice, however this may be due to the small numbers of eligible participants $(n=24)$.

\section{Funding and Ethical Considerations}

No funding was provided in the implementation of this evidenced-based practice project. Completing interest: None 
This study received exempt status from the Institutional Review Board of the associated university. 


\section{References}

Agency for Healthcare Research and Quality: Advancing excellence in health care. (2013). PlanDo-Study-Act (PDSA) Cycle. Retrieved from: https://innovations.ahrq.gov/qualitytools/plan-do-study-act-pdsa-cycle

American Academy of Pediatrics. Motivational Interviewing. (2015). Retrieved from: https://www.aap.org/en-us/advocacy-and-policy/aap-health-initiatives/MentalHealth/Pages/motivational-interviewing.aspx

Barlow, S. E. (2007). Expert Committee recommendations regarding the prevention, assessment and treatment of child and adolescent overweight and obesity: Summary Report. Pediatrics, 120 (suppl 4), S162-S192

Brandt, K. L., Booker, J. M., \& McGrath, J. (2013). Clinical quality improvement for identification and management of overweight in pediatric primary care practices. Clinical Pediatrics, 52 (7), 620-627

Centers for Disease Control. (2014). Retrieved from: https://www.cdc.gov/media/releases/2014/p0327-autism-spectrum-disorder.html

Cleave, J. V., Kuhithau, K. A., Bloom, S., Newacheck, P. W, Knapp, A. A., Homer, C. J. \& Perrin, J. M. (2016). Interventions to improve screening and follow-up in primary care: A systematic review of the evidence. Acad Pediatr, 12(4), 269-282

Coopock, J. H., Ridolfi, D. R., Hayes, J. F., St Paul, M., \& Wilfley, D. E. (2014). Current approaches to the management of pediatric overweight and obesity. Current Treatment Options Cardiovascular Medicine, 16 (11), 343. doi: 10.1007/s11936-014-0343-0 
Cygan, H. R., Baldwin, K., Chehab, L. G., Rodriguez, N. A., \& Zenk, S. N. (2014). Six to success: Improving primary care management of pediatric overweight and obesity. Journal of Pediatric Health Care, 28, 429-437

Dobber, J. Van Meijel, B., Barkhof, E., Scholte op Reimer, W., Latour, C., Peters, R., \& Linszen. (2014). Selecting an optimal instrument to identify active ingredients of the motivational interviewing-process. Journal of Psychosomatic Research. Retrieved from: http://dx.doi.org/10.1016/j.jpsychores.2014.0.010

Ebbeling, C. B., \& Antonelli, R. C. (2015). Primary care interventions for pediatric obesity: Need for an integrated approach. Pediatrics, doi: 10.1542/peds.2015-0495

Gruhl, E., Van Leuven, K. A. (2014). Motivational interviewing for Adolescent: Behavior counseling for diet and exercise. Journal for Nurse Practitioners, (10) 7, 493-499

Hampi, S., Paves, H., Laubscher, K., \& Eneli, I. (2011). Patient engagement and attrition in pediatric obesity clinics and programs: Results and recommendations. Pediatrics. 2 (128), S59-S64. doi: 10.1542/peds.2011-0480E

Lau, R., Stevenson, F., Ong, B. N., Dziedzic, K., Treweek, S., Eldrige, S., .. Murray, E. (2016). Achieving change in primary care-causes of the evidence to practice gap: Systematic reviews of reviews. Implementation Science. 11 (40), doi: 10.1186/s13012-016-0396-4

Lindeke, L. L. (2015). A call to action for care coordination research and pediatric implementation science. Journal of Pediatric Health Care, 29 (5), 474-477

Melnyk, B. M., \& Fineout-Overholt. (2011). Evidence-based practice in Nursing \& Healthcare: A guide to best practice ( $2^{\text {nd }}$ ed). Lippincott Williams \& Wilkins. Philadelphia: PA

Nordstrand, A., Fridlund, B., \& Sollesnes, R. (2016). Implementation of national guidelines for the prevention and treatment of overweight and obesity in children and adolescents: A 
phenomenographic analysis of public health nurses' perceptions. Int J Qual Stud Health Wellbeing, 11, doi: 10.3402/ghw.v11.31934

Pakpour, A. H., Gellert, Pl, Dombrowski, S. U., \& Fridlund, B. (2014). Motivational interviewing with parents for obesity: An RCT. Pediatrics, doi: 10.1542/peds.2014-1987

Porter, S., Qureshi, R., Caldwell, B. A., Echevarria, M., Dubbs, W. B., \& Sullivan, M. W. (2016). Developmental surveillance and screening practices by pediatric primary care providers: Implications for early intervention professionals. Infants \& Young Children, 29 (2), 91-101

Quanbeck, A., Brown, R. T., Zgierska, A. E., Johnson, R. A., Robinson, J. M., \& Jacobson, N. (2016). Systems consultation: protocol for a novel implementation strategy designed to promote evidence-based practice in primary care. Health Research Policy and Systems. 14 (8), doi:10.1186/s12961-016-0079-2

Radecki, L., Sand-Loud, N., O’Conner, K. G., Sharp, S., \& Olson, L. M. (2011). Trends in the use of standardized tools for developmental screening in early childhood: 2002-2009. Pediatrics, 128 (1), 14-19, doi: 10.1542/peds.2010-2180

Reed, M., Cygan, H., Lui, K., \& Mullen, M. (2015). Identification, prevention, and management of childhood overweight and obesity in a pediatric primary care center. Clinical Pediatrics, 1-7, doi: 10:1177/00009922815614350

Thompson, C., Pulleyblank, R., Parrott, \& S., Essex, H. (2016). The cost-effectiveness of quality improvement projects: a conceptual framework, checklist and online tool for considering the costs and consequences of implementation-based quality improvement. Journal of Evaluation in Clinical Practice, 22, 26-30. 
White, D.A., Rofey, D. L., Kriska, A. M., Venditti, E. M., Gibbs, B. B., Gallagher, J. D., \& Jakicic, J.M. (2016).. Parental influences on child weight: Perception, willingness to change, and barriers. Obesity \& Weight Loss Therapy 6(293). doi: 10.4172/21657904.1000293

Wittmeier, K. D. M., Klassen, T. P., \& Sibley, K. M. (2015). Implementation science in pediatric health care advances and opportunities. JAMA Pediatrics, 164(4), 307-309

Zwaigenbaum, L, Bauman, M. L., Fein, D., Pierce, K., Buie, T., ...Wagner, S. (2015). Early screening of autism spectrum disorder: Recommendations for practice and research. Pediatrics, 136: S41-S59 


\section{Table}

Table 1: Demographic information for eligible children meeting obesity criteria of $>95^{\text {th }} \% \mathrm{BMI}$

\begin{tabular}{|l|c|}
\hline $\begin{array}{l}\text { Obesity } \\
\text { Participants }\end{array}$ & $\mathbf{N = 8 2}$ \\
\hline Male & 49 \\
\hline Female & 33 \\
\hline Age Range & $5-18$ \\
\hline Race / \\
Ethnicity & Percent \\
\hline Hispanic & 45 \\
\hline NH White & 16 \\
\hline NH Black & 7 \\
\hline Mixed race & 6 \\
\hline Pacific Island & 5 \\
\hline Asian & 3 \\
\hline
\end{tabular}




\section{Figure}

Figure 1: Graphic representation of parental concern of child's weight by ethnicity and gender

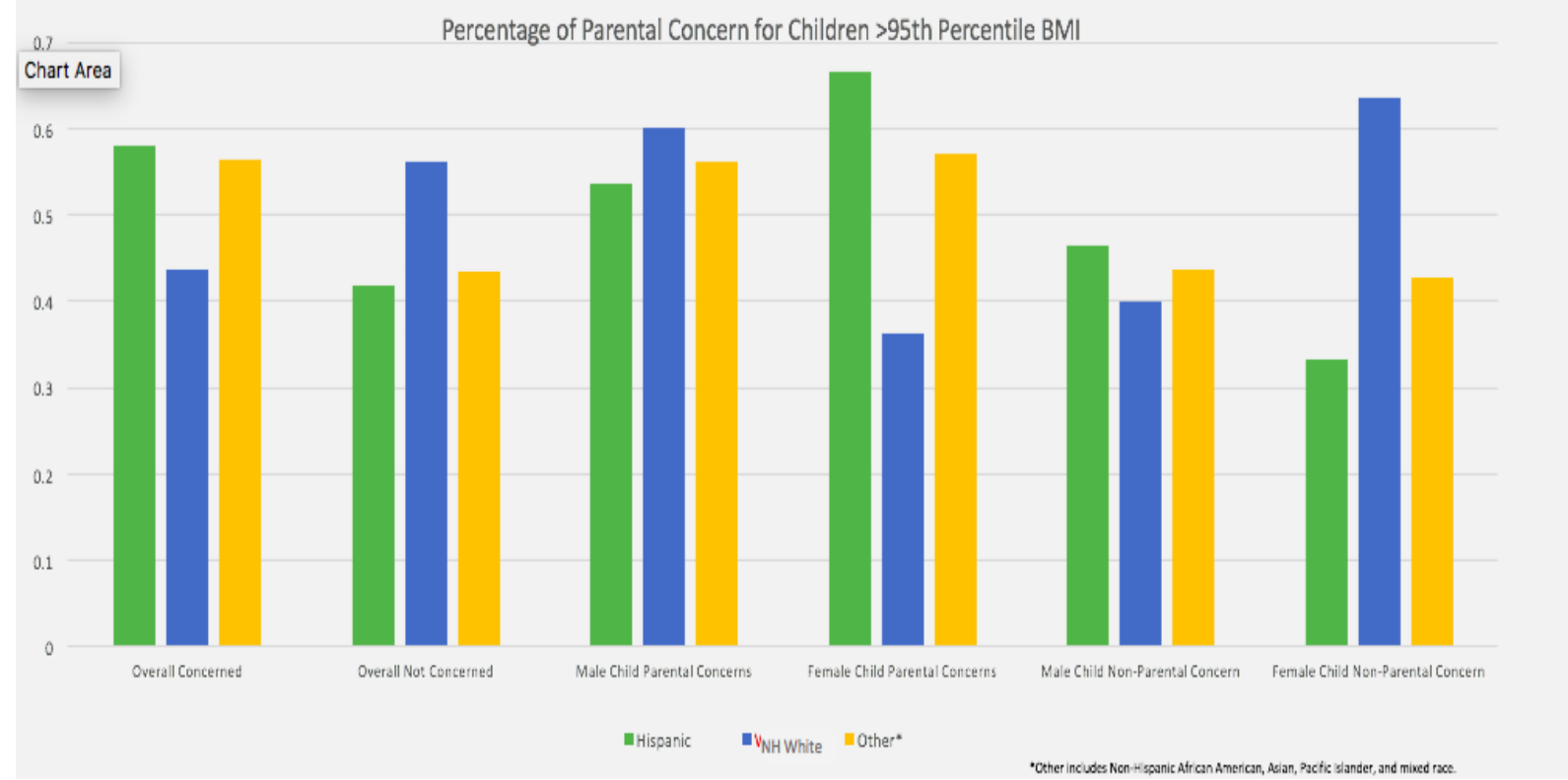

Figure 2: Uptake graph of CHPD obesity assessment form by the practice.

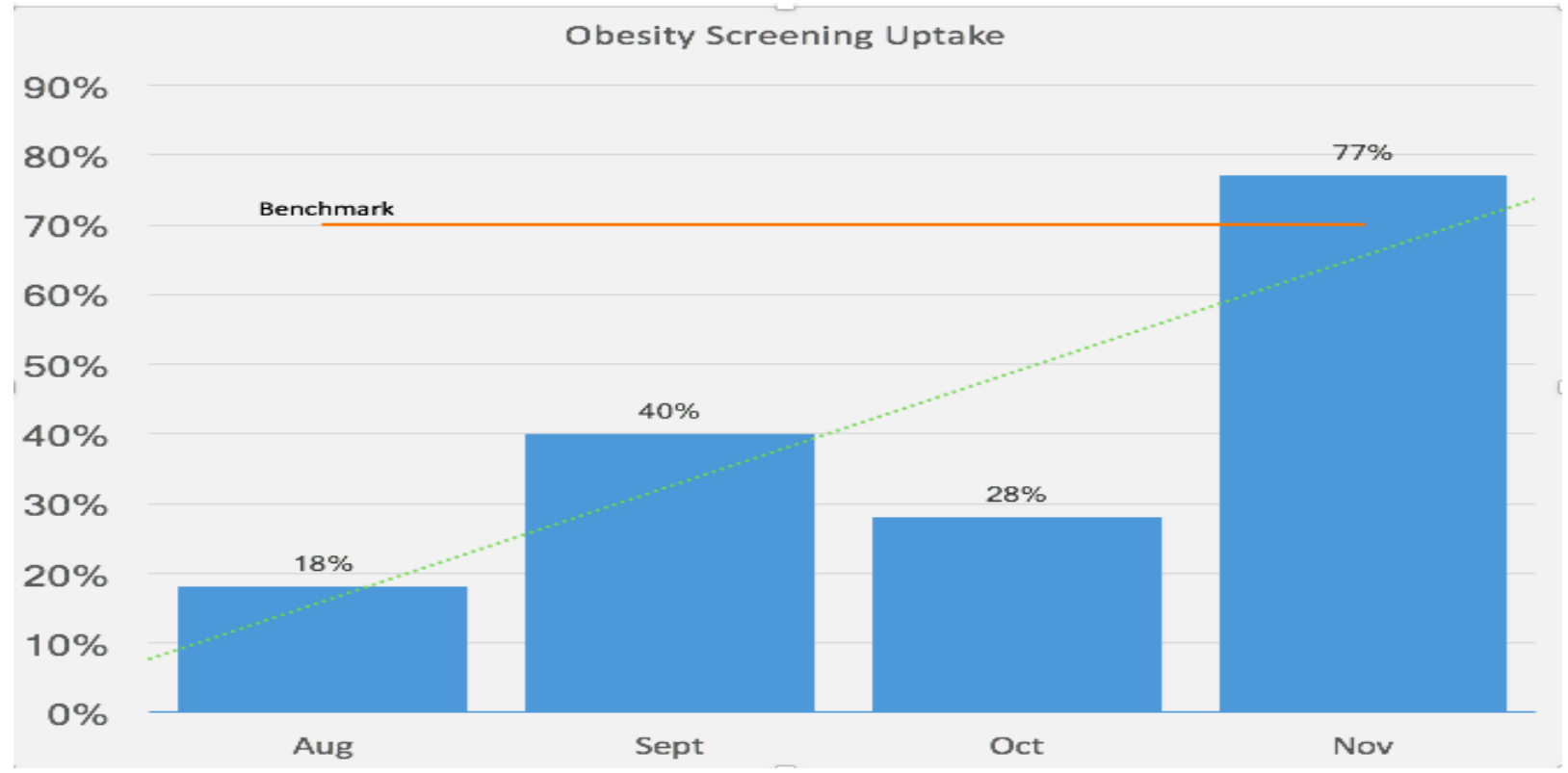

Decrease in October related to lack of NP seeing eligible children during well child visits. 
Figure 3: Uptake of MCHAT-R screening.

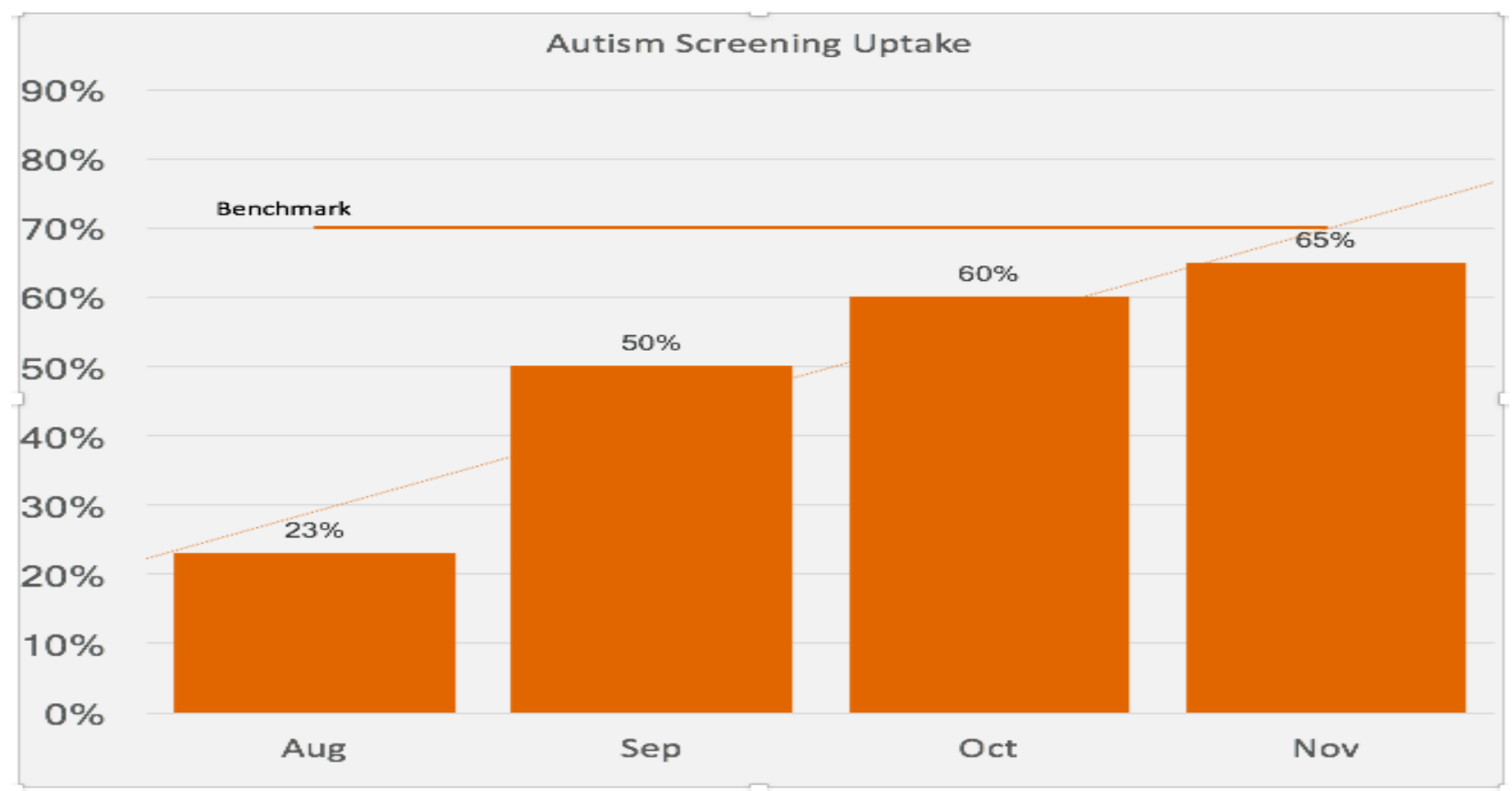

Did not meet established practice benchmark. 